\title{
EDUCAÇÃO DE MENINOS E MENINAS DE RUA EM LONDRINA
}

\author{
Clarice Junges \\ Educadora Social na Secretaria de \\ Ação Social da Prefeitura do Município de Londrina
}

Rosalice Santiago Eugenio

Especialista em Marginalização da Infância e da Adolescência.

E-mail: linhacerta@onda.com.br

\section{Resumo}

O texto aborda a história do atendimento às crianças e adolescentes pobres no Brasil e em Londrina. Descreve o contexto social da cidade e analisa a atuação do poder público municipal junto aos meninos de rua nas gestões 1993-1996 e 1997 2000 , apontando semelhanças e diferenças na maneira de conceber e conduzir o trabalho. Prioriza o olhar dos próprios meninos sobre os programas e projetos a eles destinados, concluindo que os mesmos não atendem às necessidades dessa população porque, objetivamente, buscam atender aos interesses políticos, econômicos e sociais dominantes. Avalia, ainda, que os métodos libertários propostos por educadores como Paulo Freire, Cesare La Rocca, Antonio Carlos Gomes da Costa, entre outros, são os que mais se aproximam da realidade e, consequientemente, das soluções efetivas para o problema social em questão.

Palavras-chave: criança; adolescente; educação; exclusão social.

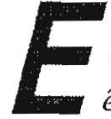

ste texto é decorrente da participação na mesa redonda Experiências Alternativas de Educação na Região de Londrina, realizada em maio de 2000 durante a Semana de Ciências Sociais da UEL, cuja temática foi Ciências Sociais e Educação: Temas e Desafios Contemporâneos. O convite foi feito a uma das autoras deste trabalho, Clarice Junges, devido a sua experiência como educadora social em projetos da Prefeitura Municipal de Londrina destinados ao atendi- 
mento de meninos de rua, e também pelo fato de ter realizado uma pesquisa para elaboração do trabalho de conclusão do curso de Ciências Sociais, na qual explorou as representações de educadores e meninos de rua sobre o atendimento a eles oferecido pelo poder público em 1994. Apesar de não estar mais atuando nos referidos projetos, a autora integra ainda um grupo formado por pessoas de diversas profissões, que realizam trabalho voluntário junto às crianças e jovens que vivem nas ruas de Londrina. Assim, a forma de exposição do tema foi discutida coletivamente e, dessa discussão, surgiu a preocupação sobre como retratar as estratégias de sobrevivência na rua e, mais que isso, como inserir essa população nesse debate, do qual foi a principal protagonista. Entendíamos, em razão mesmo do modo como nos relacionamos com esses jovens, que, num debate sobre eles, seria justo e desejável que estivessem presentes para conhecer o que se pensa e se fala a seu respeito, e também para que pudessem se manifestar, caso o desejassem.

Pareceu-nos que só falar seria muito pouco. Surgiu a idéia de produzir um vídeo para mostrar como vivem esses meninos e em que contexto social. Os meninos de rua não existem isolados no mundo; eles existem dentro de uma sociedade que exclui uma população enorme, que marginaliza e oprime muita gente, e entre essas pessoas oprimidas e marginalizadas estão os meninos de rua. Assim, com o auxílio do grupo para a coleta de imagens e o apoio técnico da UEL para a edição, produzimos Londrina nua: imagens da rua. Com 10 minutos de duração, o vídeo retrata a cidade e seus contrastes sociais para focalizar o cotidiano, os medos e os sonhos desses atores, talentosos representantes da aventura de sobreviver no universo capitalista.

As imagens e músicas do vídeo causaram grande impacto no público presente, dando a tônica da apresentação do tema. Assim, descrevemos seu conteúdo, que se tornou parte indissociável da discussão. Ficará faltando a melodia, já que a música, associada às imagens, é o meio por excelência de transmitir as mensagens.

$\mathrm{O}$ vídeo começa mostrando o lado belo e próspero da cidade, com imagens retiradas de um vídeo institucional já existente. Sob o fundo musical de Édson Cordeiro - I can't get no satisfaction passam-se imagens dos principais pontos turísticos, culturais, gastronômicos, industriais e comerciais. Ao final dessas imagens há a 
seguinte chamada: "Esperamos que você tenha gostado do passeio e que fique estimulado a conhecer mais de perto e ao vivo o que de melhor nossa cidade tem para oferecer. Venha viver Londrina!"

"Alguma coisa está fora da ordem, fora da nova ordem mundial", na voz de Caetano Veloso, é o refrão que acompanha o título e apresenta o contraste social existente na cidade, através de cenas cuja questão central é o lixo; são crianças, jovens, adultos e idosos que sobrevivem do lixo - seja trabalhando como catadores de lixo reciclável, seja alimentando-se de restos em sacos colocados nas calçadas das ruas centrais. Outras imagens, de caráter mais subjetivo, também retratam o processo de exclusão social: um jovem que cruza o centro da cidade com andar dançante, rosto coberto e peito nu; um grupo de pessoas, ocupantes de um barracão abandonado, em volta de uma fogueira, tomando seu café da manhã. Fechando essa seqüência, um menino de aparentes 10 anos, vivendo sua infância às voltas com um carrinho cheio de papelão, mais pesado que ele mesmo, driblando o trânsito de uma avenida muito movimentada, em horário de rush.

A polícia e o governo são os elementos abordados no vídeo que melhor representam o controle exercido sobre a população pobre da cidade, cujas estratégias de sobrevivência também são retratadas, ao som de Selvagem, do grupo Paralamas do Sucesso.

A fala dos meninos expressa o lado camuflado da ação policial:

"A gente às vezes tá dormindo ela vem e coloca a botina no pescoço da gente, a gente acorda assustada com a polícia, entendeu? Se fosse pela polícia já matavam tudo nós." (Junges, 1994, p.129)

A fala do prefeito municipal - oficialmente afastado do cargo pelo seu envolvimento em um grande esquema de corrupção - revela a dissonância entre o discurso e a ação governamental:

“(...) vamos continuar trabalhando, (...) com Deus no coração, trabalhando pelos humildes, pelos pequeninos, pelas famílias mais carentes aqui da cidade de Londrina." (PREFEITO promete...2000, p.6)

As armas que a cidade apresenta são, na verdade, seus mecanismos de resistência: "meninos nos sinais, mendigos pelos cantos, e 
o espanto está nos olhos de quem vê o grande monstro a se criar". As cenas partem da periferia, onde se instalam as favelas, e acompanham a trajetória de seus habitantes em busca de sobrevivência nos espaços centrais, destinados aos que aí vivem, produzem, consomem e se mantêm integrados e visíveis aos olhos do capital.

Dados socioeconômicos do município confirmam a idéia, contida nas imagens e na música, do quanto os instrumentos de repressão destinam-se a manter tudo "fora da ordem" para essa população, e tudo "em seu lugar" para a classe dominante.

"Aqui nesta casa ninguém quer a sua boa educação, nos dias que tem comida comemos comida com a mão.

E quando a polícia, a doença, a distância ou alguma discussão nos separam de um irmão, sentimos que nunca acaba de caber mais dor no coração. Mas não choramos à toa... Aqui nesta tribo ninguém quer a sua catequização, falamos a sua língua mas não entendemos seu sermão.

Nós rimos alto, bebemos e falamos palavrão, mas não sorrimos à toa...

Aqui neste barco ninguém quer a sua orientação, não temos perspectiva mas o vento nos dá a direção.

A vida que vai à deriva é a nossa condução, mas não seguimos à toa...

Volte para o seu lar, volte para lá..."

Essa é a letra da música Volte para o seu lar (Arnaldo Antunes), com a qual se inicia a seqüência de imagens específicas sobre a vida dos'meninos de rua. A cena é de um dos "mocós",' composto por uma caixa d'água e um viaduto, usados como "cozinha" e "dormitório" respectivamente. Aí fica demonstrada toda a dinâmica da convivência dos meninos e meninas que lá residem; são seus pertences e a disposição

\footnotetext{
${ }^{1}$ Mocó: qualquer espaço urbano (viadutos, pontes, construções abandonadas, terrenos baldios etc.) ocupado por grupos de moradores de rua e que se constitui em residência. O termo mocó deriva da gíria mocozar, que significa esconder, ocultar, tirar do campo de visão.
} 
destes que dão esta dimensão: os alimentos, as panelas, o fogareiro, o cobertor, roupas e calçados espalhados, a garrafa de vinho, a colcha estendida numa mureta, o jornal do dia e o cachorro guardando o espaço.

As tomadas para a composição dessa cena foram feitas em momentos diferentes de um mesmo dia. Embora o grupo não estivesse no local, a modificação ocorrida tornou possível o acompanhamento de sua movimentação, revelando parte de seu cotidiano. Um olhar leigo sobre esse lugar classificaria seus habitantes de "coitados", "bagunceiros", "incapazes", entre outros adjetivos igualmente pejorativos. Entretanto, um olhar mais profundo e sensível, que busque enxergar além das aparências, vai constatar que há, ali, uma grande capacidade de organização, um enorme feixe de potencialidades e, acima de tudo, muita resistência aos modelos autoritários, características que revelam o objetivo maior desses meninos, que é a liberdade, liberdade de ser e de viver; ser o que eles são e viver sem ter que se ajustar aos "comportamentos socialmente adequados".

Por sugestão dos meninos que foram filmados, a música tema do bloco em que aparecem, e que retrata seu dia-a-dia e seus sonhos, é "Mágico de Oz", do grupo Racionais MC's. A identificação dos garotos com a música deve-se ao seguinte conteúdo:

"Comecei a usar pra esquecer dos problemas.

Fugi de casa; meu pai chegava bêbado e me batia muito.

Eu queria sair dessa vida.

Meu sonho?

É estudar, ter uma casa, uma família...

Se eu fosse mágico?

Não existia droga, nem fome, nem polícia."

A música retrata uma identidade peculiar das crianças e jovens que vivem em situação de rua; eles compartilham de realidades familiares semelhantes, marcadas por muitos "problemas", entre os quais a violência doméstica. A droga, na rua, é usada não apenas para "esquecer dos problemas", mas passa a fazer parte de todos os momentos, até mesmo dos bons momentos, sendo uma marca dessa condição, tão nítida como o sentimento de pertencer a um grupo, o grupo da rua. Em 
meio a tudo isso, a resistência às diversas formas de submissão - à família, à polícia, ao governo - e o sonho de uma vida "normal", ou seja, a vida em família, a frequiência à escola, o acesso aos produtos e serviços inerentes à sociedade de consumo.

A característica mais marcante desse bloco é a expressão contida nos gestos, nos olhares, na postura corporal, enfim, na linguagem não-verbal, que identifica cada um deles e ao grupo como um todo, revelando os mais variados sentimentos: alegria, tristeza, nostalgia, desesperança, melancolia, confiança, revolta, afeto, indignação. Tratase de um aspecto fundamental do vídeo, que é determinante no trabalho educativo com essas crianças e jovens. Paulo Freire, uma das grandes referências em educação neste país, reforça esta concepção: "É necessário ouvir o menor, ouvir seus sentimentos, seu olhar, seus gestos, seu semblante, suas emoções"(apud Projeto..., [198-], p.6)

Fechando o vídeo ouve-se Elba Ramalho e sua "Canção da despedida", acompanhada pelos acenos e beijos da garotada e pela seguinte sequiência de idéias:

"Pra tirar todo mundo da rua eles tinham que fazer um negócio pra 'de maior', porque não tem só 'de menor' na rua. Daí eles dar serviço, todo apoio que precisar. Daí é onde ia acabar com os meninos de rua. Agora, assim do jeito que eles tão indo nunca acaba: perigoso aumentar do que acabar." (Junges, 1994, p.128)

"O chamado menino de rua é uma ilha cercada de omissões por todos os lados. Todas as políticas públicas falharam em relação a ele. A política de emprego e salário justo falhou em relação aos seus pais. As políticas de habitação, saneamento básico e urbanização já falharam em relação à sua família. Igualmente a educação e a saúde passaram ao largo de sua existência. A única política a dar a esse menino a atenção continuada e sistemática é a política de segurança pública." (Costa, 1989, p.74-75)

"O nosso amor por esses meninos negados no seu direito de ser, só se expressa autenticamente quando o nosso sonho é o de criar um mundo diferente."(Freire apud Projeto..., [198-], p. 13)

Na sequiência de frases parece estabelecer-se um diálogo desses jovens com Paulo Freire e Antônio Carlos Gomes da Costa, dois 
grandes educadores, apaixonados defensores dos seus direitos, sobretudo do direito à educação. Mas não de qualquer educação, e sim uma educação libertária, que assuma o compromisso com o oprimido, escute verdadeiramente seus anseios, reconheça suas potencialidades e se proponha a construir, junto com os educandos, um mundo diferente.

É importante ressaltar que a música faz parte do universo desses meninos de uma maneira muito peculiar; eles se apropriam da linguagem musical com a qual se identificam, fazendo dela um instrumento para expressar seus sentimentos e justificar seu modo de vida. Tanto é que, após a exibição do vídeo, uma das jovens presentes no evento pediu para cantar uma música que, segundo o grupo, havia faltado no vídeo, e que é imprescindível para a compreensão da sua realidade. Trata-se de "Garoto de rua", interpretada por Zezé di Camargo e Luciano.

O principal fator que nos aproxima dessa população é, justamente, uma grande identificação com a sua forma de pensar, de reagir, de se expressar, de compreender a realidade que a cerca, enfim, com sua forma de ver o mundo. Por essa razão, em determinado momento de nossa atuação profissional, quando adotamos metodologias de educação fundamentadas nos autores já citados, entre outros que acreditam nos mesmos princípios, tivemos de escolher entre a função de educadoras sociais e a função de servidoras municipais nos projetos de atenção a crianças e adolescentes; a escolha pela primeira nos aproximou ainda mais desses meninos porque, citando novamente Paulo Freire, concluímos ser esta a única opção neste trabalho:

"O importante é saber por quem estamos fazendo opção e aliança. É o oprimido e não o opressor. Estamos do lado do menino, do explorado, do oprimido. Há uma identificação com os interesses das classes populares." (Freire apud Projeto..., [198-], p.6)

A história do atendimento às crianças e adolescentes filhos das classes populares no Brasil é marcada por sucessivos enganos, onde a questão central sempre foi assegurar à sociedade a manutenção dos sistemas político, econômico e social, impondo, dessa forma, a rotulação das crianças e adolescentes pauperizados conforme os padrões socialmente dominantes. 


\section{Segundo Alvim \& Valadares,}

"Se foram várias as respostas oferecidas ao problema todas elas basearam-se numa mesma concepção da infância pobre como necessariamente perigosa e conseqüentemente ameaçadora. A integração à ordem estabelecida sempre se colocou como necessária, mas os menores, por permanecerem à margem (da lei e dos benefícios da sociedade), sempre foram excluídos de um projeto nacional." (Alvim \& Valadares apud Junges, 1994, p.23)

Nessa perspectiva o Brasil viu crescer o número de crianças e adolescentes que romperam e negaram o que lhes foi imposto e foram às ruas lutar por meios de sobrevivência que, apesar de arriscados, lhes garantiam um mínimo de liberdade para exercerem seu papel na sociedade, ou seja, negar-se à situação de miserabilidade, revelar a decadência das políticas públicas a eles aplicadas e, principalmente, "incomodar" uma sociedade que, tendo marginalizado suas famílias, também os marginalizou, roubando-lhes o direito à igualdade, à dignidade e à cidadania.

Até o início do regime militar de 1964 predominou a mentalidade de que "problema social é caso de polícia". As crianças e adolescentes pobres, os "menores", ${ }^{3}$ representavam uma das maiores ameaças sociais da época. O governo federal instaurou, naquele mesmo ano, a lei $\mathrm{n}^{\mathrm{o}}$ 4.513, que continha as diretrizes e bases para a Política Nacional do Bem-Estar do Menor. A implementação dessa lei foi viabilizada pela FUNABEM - Fundação Nacional do Bem-Estar do Menor, órgão normativo federal, e através das FEBEMs - Fundações Estaduais de Bem-Estar do Menor, órgãos executores do atendimento no âmbito estadual. Essa política visava, antes de tudo, corrigir, regenerar, refor-

\footnotetext{
2 "Dados do IBGE indicam que 53,5\% das crianças e adolescentes brasileiros vivem em situação de pobreza, em famílias cuja renda per capita não ultrapassa $1 / 2$ salário mínimo "(Trabalhando..., 1993, p.9).

3 "Embora aplicando-se a todos os menores legais, este termo não se aplica a todos da mesma maneira nem com o mesmo sentido. Na sua ambigüidade, o termo menor tornou-se indicador de certa categoria de criança/adolescente que, pela sua origem, constitui um problema para a sociedade. Ele serve, assim, para sinalizar no corpo social zonas de alto risco que o Estado deve vigiar através de seus aparelhos de controle social" (Pino, 1987, p.45).
} 
mar tais "menores" no interior das instituições, para devolvê-los ao convívio social com a roupa de "cidadãos ordeiros", que respeitam a lei, a ordem, a moral e os bons costumes, cerceando-lhes a infância e a juventude com a desculpa de educá-los.

A prática dessas instituições, fundamentada no enfoque correcional-repressivo, foi enfraquecida pela realidade que as crianças e jovens insistiam em denunciar. Surge então, no período de modernização conservadora da vida brasileira, uma nova maneira de entender o problema: a ótica assistencialista.

"O assistencialismo dirige-se à criança e ao jovem perguntando pelo que ele não é, pelo que ele não sabe, pelo que ele não tem, pelo que ele não é capaz. Daí que, comparado ao menino de classe média, como padrão da normalidade, o menor marginalizado passa a ser visto como carente bio-psico-sócio-cultural, um feixe de carências." (Costa, $1989, \mathrm{p} .82)$

Mais um engano. Novamente as crianças e adolescentes são padronizados e se institui como modelo básico de atendimento em todo o país a tentativa de restituir, resgatar e devolver ao menor marginalizado o que lhe havia sido sonegado no âmbito das relações sociais.

Essa visão esquece que crianças e adolescentes têm sonhos e particularidades muito próprios dessas fases de desenvolvimento, em que seus interesses são coloridos, saborosos e dinâmicos e que suas vidas refletem isso num mundo que parece ter sido feito especialmente para que possam brincar, como se a rua fosse um grande parque de diversões, uma terra de gigantes. Falhou-se mais uma vez, porque esse modelo de atendimento não perguntou a eles o que pensavam, sabiam e queriam e, para "dar certo", o assistencialismo - até pela estrutura funcional - conviveu com práticas do enfoque correcional-repressivo, estabelecidas pelo regime militar. Apenas no final dos anos 70 , quando crianças e adolescentes passam a ser entendidos como tais, e não como "pequenos adultos", e quando educadores e trabalhadores sociais começam a emergir no processo de abertura democrática, é que se estabelece o respeito ao menor marginalizado e surge, finalmente, 0 modelo que prioriza a educação progressista. 
"O menino deixa de ser visto como um feixe de carências e passa a ser percebido como sujeito de sua história e de seu povo, como um feixe de possibilidades abertas para o futuro. Agora se pergunta o que ele é, o que ele sabe, o que ele traz e do que ele é capaz." (Costa, 1989, p.83)

Essa é, resumidamente, a história do atendimento que se ofereceu à criança e ao adolescente pobres - entre eles os meninos de rua - no Brasil até os anos 80 , e que ainda coexiste com as novas formas de pensar e agir em relação a eles. Como processo histórico, a marca do enfoque anterior acompanha cada nova tentativa, ou seja, práticas correcionais-repressivas misturam-se com práticas assistencialistas e educativas.

No início da década de 80 percebeu-se que, por mais que se aproximassem da realidade a ser trabalhada, as práticas das instituições não tinham sido capazes de quebrar o ciclo apreensão-triagem-rotulaçãodeportação e confinamento nas prisões e depósitos do governo.

À luz desse entendimento começa a ser discutido o Estatuto da Criança e do Adolescente (ECA) - implantado em 1990 - que traz uma nova maneira de encarar o problema da criança e do adolescente no país, contemplando principalmente a situação de risco e de degradação pessoal e social a que estão expostos os meninos e meninas de rua.

A concepção sustentadora do ECA á chamada Doutrina da Proteção Integral.

"Essa doutrina afirma o valor intrínseco da criança como ser humano;
a necessidade de especial respeito à sua condição de pessoa em desen-
volvimento; o valor prospectivo da infância e da juventude como por-
tadoras da continuidade de seu povo, da sua família e da espécie huma-
na; e o reconhecimento da sua vulnerabilidade, o que torna as crianças
e adolescentes merecedores de proteção integral por parte da família,
da sociedade e do Estado, o qual deverá atuar por meio das políticas
específicas para o atendimento, promoção e defesa de seus
direitos."(Costa,1994, p.24)

Dessa forma, o ECA garantiu proteção integral não só às crianças e adolescentes, mas também às suas famílias.

Ainda que sejam classificadas pelos diversos organismos de assistência social e pela sociedade em geral como "desestruturadas" e 
"desorganizadas" e apontadas como "culp̧ad «s" pela situação de abandono de seus filhos, as famílias são, na verdade, as que mais precisam de proteção, para poder criá-los.

Ao contrário do que se pensava em décadas anteriores, as crianças e adolescentes às quais nos referimos não são "abandonadas", embora haja, sim, uma tendência ao enfraquecimento dos laços familiares na medida em que se estabelecem as relações sociais no espaço da rua. As famílias nucleares predominam, embora uma parcela significativa seja organizada apenas em torno da mãe. As ocupações de baixa qualificação e o desemprego também predominam entre os chefes dessas famílias.

Os conflitos familiares decorrentes dessa realidade (violência, abuso sexual, instabilidade nas relações conjugais, exploração do trabalho infantil) determinam, muitas vezes, o afastamento definitivo da criança e do adolescente, reforçando seu vínculo no mundo da rua em contraposição ao da casa.

Considerando os aspectos estruturais que determinam a condição social dos pais desses meninos e meninas que hoje estão ou vivem nas ruas, cabe perguntar, como Pino (1987, p.39):

"Se há um processo de exclusão — o que implica, por definição, um ato externo à vontade dos excluídos - como atribuir às características das populações excluídas a razão da sua não integração?"

É nessa compreensão da exclusão social imposta a essa população que deve pautar-se o trabalho a ser realizado com crianças e adolescentes, visando assegurar-lhes seus direitos fundamentais: vida, saúdle, alimentação, educação, esporte, lazer, profissionalização, cultura, dignidade, respeito, liberdade, convivência familiar e comunitária (ECA, art. $4^{\circ}$ ).

Um rápido olhar sobre algumas matérias dos jornais locais nos ajudará a traçar um histórico do atendimento am nível municipal:

"O EXÉRCITO DE CRIANÇAS CARENTES: Em Londrina elas são 20 mil. E não se tem uma solução a curto prazo." (Folha de Londrina, 31 dez. 1980) 
"MUDANÇA DE ORIENTAÇÃO E CORTE DE VERBAS CONFUNDEM ENTIDADES QUE CUIDAM DE MENORES CARENTES." (Folha de Londrina, 19 maio 1983)

"SEM ABRIGO, CRIANÇAS SE AMONTOAM NAS CALÇADAS PARA FUGIR DO FRIO." (Folha de Londrina, 13 jul. 1985)

"PASTORAL COMEÇA A TRABALHAR COM MENOR CARENTE NA PRÓPRIA RUA." (Folha de Londrina, 30 nov. 1986)

"DOS MAIORES PROBLEMAS, O MENOR É PARA LONDRINA: Londrina convive, talvez sem saber, com um contingente de 58 mil menores que vivem em condições desumanas. A Secretaria de Saúde e Promoção Social do Município sabe disto. E vem articulando esforço conjunto com a sociedade para mudar este cenário." (Folha de Londrina, 4 mar. 1990)

"ALBERGUE INFANTIL PODE TIRAR MENORES DA RUA." (Folha de Londrina, 7 mar. 1991)

"MENORES DE RUA SONHAM COM UMA CASA, MOSTRA PESQUISA." (Folha de Londrina, 23 out. 1991)

"LONDRINA TEM 25 MIL MENORES ABANDONADOS: São crianças que vivem na pobreza ou largadas nas ruas, sem a mínima assistência da comunidade." (Folha de Londrina, 28 fev. 1992)

"POLÍTICA DO MENOR PRECISA DE REESTRUTURAÇÃO TOTAL: O que é feito atualmente não condiz com a crítica situação das centenas de menores de rua em Londrina." (Folha de Londrina, 1 mar. 1992)

"LONDRINA TEM 200 MENORES VIVENDO NAS RUAS: Psicóloga ouviu meninos e meninas que ganham dinheiro nas ruas da cidade, como catadores de papel, guardadores de carro ou pedindo esmola." (Jornal de Londrina, 11 jul. 1992)

“'MENORES DE RUA SÃO UMA BOMBA RELÓGIO': Hostilizados pela sociedade, os meninos de rua têm poucas chances de vencer na vida. Londrina tem 350 menores considerados delinquientes." (Correio Londrinense, 25 out. 1992) 
"Baderna: MENORES DEPREDAM LOJAS EM LONDRINA: Eles estavam revoltados com o fechamento do albergue onde dormiam e se alimentavam." (Folha de Londrina, 30 out. 1992)

"ADOLESCENTES COM FOME ATACAM LOJAS: Interceptados pelos policiais perto do Zerão, meninos disseram que iam à Prefeitura reclamar do fechamento do Albergue Infantil." (Jornal de Londrina, 30 out. 1992)

“ARRASTÃO É UM ALERTA PARA PREFEITO: O futuro prefeito de Londrina vai se deparar com o problema do menor abandonado, que está alarmando a sociedade." (Correio Londrinense, 30 out. 1992)

"LONDRINA AINDA ASSUSTADA COM MENORES: A polícia foi chamada várias vezes por comerciantes e moradores. Não houve ocorrência grave. Prefeitura oferece 4 casas. Policiamento é reforçado." (Folha de Londrina, 31 out. 1992)

"POLÍCIA EM ALERTA CONTRA MENORES DE RUA: Ontem à tarde novos distúrbios ocorreram. Polícias prometem rigor. Estado anuncia CR $\$ 22$ milhões." (Folha de Londrina, 4 nov. 1992)

Embora o problema estivesse latente no município desde os anos 50, nas décadas de 80 e 90, com sua intensificação, a cidade e as autoridades no assunto debatiam-no intensamente, reconhecendo sua existência e gravidade, mas sem encontar soluções efetivas. Chegou a hora em que os próprios "menores" tomaram uma atitude. Note-se que até então esses meninos apareciam nos jornais como "crianças carentes", "menores carentes", "menores de rua", "meninos de rua". E quando resolveram tomar uma atitude concreta, manifestando sua revolta e indignação pelo fechamento da única estrutura de atendimento a eles destinada, passaram a ser classificados — pelo jornal de maior circulação do município - como "baderneiros", constituindo-se caso de polícia, problema de "segurança pública", e recebendo dessa política seu costumeiro atendimento.

Da administração que assumiria o poder público em breve (gestão 1993-1996) esperava-se a solução. Tão logo assumiu, mostrou realmente como intencionava resolver o problema: 
"MENORES DE LONDRINA GANHAM ABRIGO: Além de tirar as crianças do relento, a prefeitura pretende recuperá-las."(grifamos) (Jornal de Londrina, 29 jan. 1993)

"PROGRAMAS TIRAM OS MENINOS DAS RUAS: Vida em 'família' nas casas-abrigo. Da cola para o futebol." (Folha de Londrina, 21 mar. 1993).

"Filhos da Miséria: LONDRINA REAGE E TIRA MENOR DAS RUAS. A depredação de lojas no ano passado serviu de alerta. E a prefeitura se lança em socorro dos meninos e meninas abandonados." (Folha de Londrina, 2 out. 1993).

Apesar da implantação de programas e projetos voltados ao atendimento dos meninos de rua, e do esforço do poder público em promover a conscientização da população a respeito das condições sociais desses jovens e de suas famílias, a imprensa escrita insistia em defini-los com termos próprios do vocabulário policial:

"Segurança: MENORES DE RUA DESAFIAM LONDRINA: Divididos em quadrilhas eles são responsáveis por $70 \%$ dos furtos e roubos da cidade" (Folha de Londrina, 6 jun. 1993).

Os meninos, por sua vez, criavam novas estratégias de sobrevivência, desenvolviam mecanismos para driblar não só a polícia e as dificuldades próprias do ambiente da rua, mas também as equipes de atendimento social, para que pudessem "merecer" seu atendimento sem abrir mão de princípios essenciais: o prazer da liberdade e o respeito à sua identidade. Assim, apesar da existência de casas-abrigo para "menores", eles procuravam nos espaços públicos abandonados o aconchego do lar:

"Meninos de rua: POLÍCIA ESPERA AUTORIZAÇÃO PARA DAR BATIDAS NA CONCHA. Saquinhos de cola na mão, os meninos e meninas dizem que já se acostumaram na rua" (Jornal de Londrina, 29 out. 1993).

“PROJETOS SOCIAIS NÃO CHEGAM AOS 'MOCÓS': Secretaria da Ação Social tem dificuldade para trabalhar com menores que se fixam em imóveis abandonados" (Folha de Londrina, 6 jul. 1994). 
"ARRASTÃO NA MADRUGADA DEIXA A CIDADE APAVORADA: Menores danificam carros, furtam lojas e ameaçam transeuntes" (Folha de Londrina, 29 jan. 1995).

A solução prometida pela administração que assumira o poder público no início de 1993 mostrava já suas limitações; os esforços para tirar os meninos das ruas tinham sido, em grande medida, inúteis. $\mathrm{E}$ assim caminhavam os projetos, e cresciam os meninos, reproduzindo o ciclo rua/mocó-casa-abrigo-rua-família-rua/mocó.

No início de 1997, com o novo governo municipal (gestão 19972000), "novas" propostas de solução foram apresentadas, "novos" projetos foram implantados:

"Menores abandonados: OS IGNORADOS HABITANTES DE UM LUGAR CHAMADO RUA. Prefeitura diz que a sociedade precisa cumprir a sua parte na busca de soluções" (Folha de Londrina, 9 fev. 1997).

"CASAS-ABRIGO FECHAM E MENORES VOLTAM À RUA. UM FOI BALEADO" (Jornal de Londrina, 26 abr. 1997).

"ENTRE A AÇÃO E A OMISSÃO: Londrinense faz doações, mas não quer casas-abrigo na vizinhança. Cidade terá campanha contra as esmolas. Ação Social dará prioridade a trabalho com famílias" (Folha de Londrina, 25 maio 1997).

"Ação Social: PROJETO QUER TIRAR DAS RUAS 130 MENORES EM 'SITUAÇÃO DE RISCO': Equipe vai percorrer Londrina para encaminhar (grifamos) meninos e meninas para a família ou para a casa-abrigo" (29 maio 1998).

"Meninos de rua: APOIO E CARINHO AJUDAM NA RECUPERAÇÃO: Nas casas-abrigo garotos reaprendem a convivência" (31 maio 1998).

“MENOR EM MOCÓ É PROBLEMA POLÍTICO: Ex-secretária da Ação Social critica a atual e diz que Secretaria tem que assumir responsabilidade com menores" (Jornal de Londrina, 4 dez. 1998).

"CASA QUE ABRIGA MENORES SERÁ FECHADA: A desativação da Chácara Igapó é consequiência do rompimento de um convênio entre o Estado e a Prefeitura de Londrina" (Folha de Londrina, 25 maio 2000) 
Há algumas diferenças significativas entre as duas últimas administrações municipais na condução da política de atenção à criança e ao adolescente em situação de rua. No discurso da gestão 1993-1996 estava implícito que o atendimento que se prestava a essa população era de responsabilidade e competência do Estado, ou seja, do poder público, por ser um direito expresso na Constituição Federal e no ECA. Na gestão 1997-2000 prevalece o discurso da competência do Estado, porém muito mais no âmbito do controle das políticas públicas do que da efetiva execução das ações, as quais são cada vez mais delegadas às entidades assistenciais e à sociedade em geral. Trata-se de um reflexo, em nível local, dos princípios neoliberais que norteiam o atual governo nacional.

No que se refere, porém, à atuação prática dos projetos do poder público junto às crianças e adolescentes que vivem nas ruas, há uma semelhança muito grande entre as duas gestões. A característica mais marcante dessa semelhança é a concepção sobre a obrigação que o poder público tem de atender aos interesses "da sociedade" - entenda-se interesses das classes dominantes da sociedade - já que sempre cederam às pressões dos empresários para tirar os meninos das portas de suas lojas, deixando de ouvir a necessidade de eles serem atendidos no próprio espaço da rua, com atividades que pudessem suscitar-lhes o desejo de viver em outro espaço. Não respeitaram o tempo dos meninos, sempre retirados às pressas da rua e "encaminhados" para alguma das estruturas de "recuperação": casas-abrigo, clínicas para usuários de drogas, escolas especiais para meninos de rua, centros de internamento e unidades de semiliberdade destinadas a adolescentes infratores. É válido ressaltar que segundo o ECA toda essa estrutura deve servir de apoio ao trabalho de proteção integral, o qual deve ser desenvolvido no município onde residem as famílias dessas crianças e adolescentes. Em Londrina, porém, é comum a realização de encaminhamentos para clínicas localizadas em outras cidades ou até mesmo em outros estados. Nesses casos, a convivência familiar e comunitária, direito fundamental registrado no ECA, fica, na maioria das vezes, impossibilitada.

Outro aspecto semelhante nas duas administrações é a forma como elas conduzem as questões relativas aos recursos humanos que atuam nos projetos de atendimento a crianças e adolescentes. Os pro- 
fissionais da área - educadores sociais e auxiliares educativos sempre estiveram sujeitos à instabilidade das contratações, na maioria das vezes temporárias, aos baixos salários e a longas jornadas de trabalho. Não se exige desses profissionais, como requisito para sua contratação, uma formação específica, e também não há, por parte da prefeitura, uma real capacitação que anteceda a atuação. $\mathrm{O}$ aprendizado, os acertos e erros vão acontecendo na prática. Lamentavelmente, os erros, superam de longe os acertos.

Apesar dessas precárias condições de trabalho, muitos buscam, em razão do envolvimento e do compromisso que vão estabelecendo com essa garotada, alternativas condizentes com o anseio de seus educandos. Acabam por estabelecer uma metodologia educativa fundamentada na troca; descobrem-se, em determinados momentos, educadores e, em outros, educandos. Entendemos ser essa a prática que garante a eles o estabelecimento de vínculos verdadeiros, afetivos, determinantes para o desenvolvimento de um trabalho sólido, frutífero, duradouro.

Nas duas administrações, portanto, falta respeito às relações emocionais, psicológicas, afetivas estabelecidas pelos meninos, seja entre eles, seja entre eles e os educadores. A todo momento o poder público quebra os referenciais que os meninos constroem, ou porque os "encaminha", separando-os de suas famílias e de seu grupo na rua, ou porque substitui as pessoas com as quais decidem compartilhar suas angústias, alegrias, medos, desejos, enfim, sua vida.

Nesse contexto, as crianças e adolescentes possuem opiniões bem definidas sobre o atendimento que lhes é destinado pelos projetos assistenciais e sobre o que esperam dos educadores sociais:

"Nós quer uma casa pra nós morar, porque aquela lá não aceita nós. Não aceita nós por quê? Por que não aceita nos?” (Junges, 1994, p.120)

“Então, eles já não aceitam outras pessoas - que nem a gente da rua assim -, porque pensam que a gente não vai querer se adaptar, [que] a gente vai querer dar problema" (ibidem, p.123)

"Essa casa aí não presta, tia! (...) Não deixou nós entrar na casa, falou que pra nós não tem mais chance" (ibidem, p.99) 
“(...) Nessas casas devia ter uma pessoa pra poder dizer, assim... pra poder tirar a gente das drogas, entendeu? Pra poder ajudar a gente a sair das drogas. Mas não, eles não falam isso... se quiser cheirar, cheira pra fora. Isso não se fala, porque a gente vai pegando mais o vício ainda. (...) A gente não vai xingar eles por eles tentar ajudar a gente, né? A gente vai reconhecer que eles tão querendo ajudar. Mas não, eles falam assim, como se a gente não fosse nada, como se tivessem obrigação de dar um lugar pra gente pousar, pra gente dormir; é como por obrigação" (ibidem, p.123)

"É, quando tinha as tia boa, tiraram as tia boa... As tia que é boa tiraram tudinho dos projetos!" (ibidem, p.124)

"Tio legal é aquele que entende o menor de rua; agora, tio xarope é aquele que não entende e quer mandar no menor" (ibidem, p. 124).

"Tem alguns tios que ainda compreendem a gente, que a gente é viciado e tal; sabem que algum dia nós vai colocar na nossa cabeça que nós vai parar, né, meu? Isso quem tem que decidir é nós não eles. (...) Lá no mocó os tios nem vai lá tomar saquinho de cola; lá eles tá ligado que eles já levam pedrada. (...) Agora, o tio Jorge não precisava nem pedir... Nós combinava entre nós mesmo, entre nós pra nós ficar sem cheirar cola. (...) Tem que colocar uns educador que sabe entender a gente. Não adianta nada colocar um educador novo lá que não sabe de nada, não sabe ainda qual é a cabeça dos moleques de rua. Aí ninguém fica mesmo. (...) Porque nós cheira saquinho escondido... Um dia nós vai chegar nos tios e dar o saquinho na mão deles, pra eles botar fogo pra nós. Aí nós vai pedir um serviço pra eles..." (ibidem, p.127)

Várias das crianças e adolescentes que participaram das entrevistas realizadas em 1994 estiveram presentes no evento que originou este artigo. Na fala de um deles, um jovem de 24 anos que representava o grupo, encontramos ainda os mesmos componentes registrados nas falas acima:

"O que eu quero é falar pra vocês que a gente que vive na rua, a gente não quer ficar dependendo de drogas, do uso de drogas, de roubo, assalto. (...) As pessoas passam por mim quando estou muito chapado na rua e falam que eu sou marginal, mas eu não sou marginal. A sociedade fala que nós somos moleques de rua. Tem uns que é menores, outros são maiores de rua. (...) Eu já fíquei em todas as instituições...(...) A Ação Social falava que eu não tinha mais jeito. Então eu erguia a cabeça e falava: 'meu Deus, o que eu vou fazer da vida? (...) O que vai ser do meu futuro? Se eu vou ser marginal, ou assaltante, ou trafican- 
te?' (...) Eu queria agradecer se um dia a sociedade falasse assim: 'vamos providenciar outros coordenadores de rua pra dar atividades pra esses moleques que ficam na rua' (...)."

Diante desse depoimento, podemos concluir que mesmo tentando adequar as políticas públicas aos princípios do ECA, o poder público municipal e as entidades que se propõem a atender essas crianças e jovens não os entendem, nem os atendem efetivamente, porque até agora não modificaram sua concepção, sua mentalidade, a ponto de quererem criar um novo jeito de se relacionar, de trabalhar, de viver. Enfim, de construir uma sociedade mais livre e justa, inventar um mundo diferente.

\section{Referências Bibliográficas}

COSTA, Antonio Carlos Gomes da. Infância, juventude e política social no Brasil. 1989. mimeo.

O Estatuto da Criança e do Adolescente e o trabalho infantil no Brasil: trajetória, situação atual e perspectivas. São Paulo: Ltr., 1994.

BRASIL. Lei 8.069, de 13 julho de 1990. Estatuto da Criança e do Adolescente. São Paulo: Saraiva, 1990.

JUNGES. Clarice. A cidade-mãe e sua prole: estudo das representações dos educadores e meninos de rua de Londrina. 1994. Trabalho Conclusão de Curso (Bacharel em Ciências Sociais) -Universidade Estadual de Londrina. Londrina, 1994.

PINO, Angel. A questão do menor e o significado da infância na sociedade burguesa. Educação e Sociedade, ano 9, p.32-49, dez.1987.

PREFEITO promete recorrer ao Tribunal de Justiça. Folha de Londrina, Londrina, 16 maio 2000. Editorial de Política, p.6. 
PROJETO Alternativas de atendimento a meninos de rua. In: Paulo Freire \& educadores de rua: uma abordagem crítica. Rio de Janeiro: Lidador, [198-].

TRABALHANDO abrigos. Cadernos de Ação, São Paulo, n.3, mar. 1993.

\section{Abstract}

This text deals with the history of the care for poor children and adolescents in Brazil and in Londrina. It describes the social context of the city and analyses the performance of the municipal public authority related to the street boys during the administration periods of 1993-1996 and 1997-2000, indicating similarities and differences in terms of realizing and conducting this task. It prioritizes the boys evaluation of the programs and projects especially designed for them. They come to the conclusion that these programs do not fulfill the needs of this population because they objectively want to fulfill the predominant political, economical and social interests. It also evaluates that the libertarian methods proposed by educators such as Paulo Freire. Cesare La Rocca, Antonio Carlos Gomes da Costa among other, are the ones that come more closely to reality and, consequently, of the effective solutions for the social problem in question.

Key-words: child; adolescent; public authority; social exclusion. 